\title{
AN AUTOMATIC MONITORING AND CONTROL SYSTEM INSIDE GREENHOUSE
}

\author{
In partial fulfillment of the requirements \\ for the degree of \\ Bachelor of Science \\ in Electrical and Electronic Engineering
}

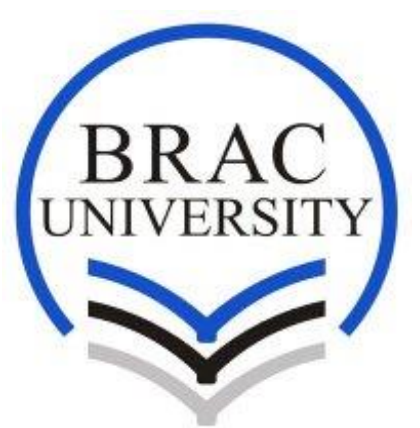

Submitted By

MD. NIAMUL HASSAN

ID: 09210022

AHMAD SHAMS NOOR

ID: 09210012

SHIHAB IBNE ABDULLAH

ID: 09210029

April 2015 


\section{DECLARATION}

We do therefore declare that the thesis titled "An Automatic Monitoring and Control system inside Greenhouse" is submitted to the Department of Electrical and Electronic Engineering, BRAC University for the fulfillment of degree in Bachelors of Science in Electronics and Communication Engineering. In addition, we announce that this is our unique work and has not been submitted anywhere for the honor of any other degree or any other publication.

Submitted By

Md. Niamul Hassan

Ahmad Shams Noor

Shihab Ibne Abdullah

Signature of the Supervisor

Ms. Marjia Alam

Department of Electrical and Electronic Engineering

Brac University 


\section{ACKNOWLEDGEMENT}

To start with, we would like to thank the Almighty Allah to achieve us at the fruitful end of the project. We might likewise want to express our gratitude to our regarded supervisor, Ms. Marzia Alam, Senior Lecturer, Department of Electrical and Electronics Engineering, BRAC University for her continual direction and support. Also we would like to thank her for helping us by giving proper counsel with the framework gadgets, framework planning and other documentation. Our special thanks to Mr. Subroto Das and Mr. Jamiur Rahman for helping us and giving their precious time and dedication throughout the project. 


\begin{abstract}
In this work, we have proposed a framework that can gather the data identified with greenhouse environment and yield status and control the system automatically in view of the gathered data. By throatily observing periodic conditions, this study has the reason for securing connection between sensors flags and reference estimations. Control programming will give information finding of ongoing show. Through long time running and functional utilizing, the framework has been demonstrated that it has numerous points of interest. To monitor the environment inside greenhouse different parameters have been considered such as light, temperature, humidity, soil moisture etc. using different sensors like DHT22 temperature and humidity Sensor, LDR, grove-moisture sensor etc. which will be interfaced with microcontroller. It is a closed loop system that will execute control action to adjust temperature, humidity, light intensity and soil moisture if any unwanted errors (high/low) occur.
\end{abstract}




\section{TABLE OF CONTENTS}

CHAPTER 1: INTRODUCTION

1.1 BACKGROUND AND MOTIVATION 9

$\begin{array}{lll}1.2 & 10\end{array}$

1.3 OBJECTIVE OF THE PROJECT 11

1.4 OUTLINE OF THE PAPER 11

CHAPTER 2: OVERVIEW OF THE PROJECT AND SETUP 12

2.1 SYSTEM OVERVIEW 13

2.2 COMPONENTS 13

$\begin{array}{lll}2.2 .1 & \text { ARDUINO } & 14\end{array}$

2.2.2 RELAY MODULE 15

$\begin{array}{lll}2.2 .3 & L C D & 15\end{array}$

CHAPTER 3: SENSORS 16

$\begin{array}{llll}3.1 & L D R & 17\end{array}$

3.2 DHT-11 TEMPERATURE AND HUMIDITY SENSOR 18

3.2.1 TECHNIAL SPECIFICATION

3.3 GROVE SOIL MOISTURE 20

3.3.1 FEATURES 20

CHAPTER 4: TEST RESULTS AND ANALYSIS 21

4.1 LIGHT SENSITIVITY (LIGHT SENSOR USING ARDUINO) 23

4.1.1 MONITORING 25

$\begin{array}{lll}4.1 .2 \text { CONTROL } & 25\end{array}$

4.2 DHTI1 TEMPERATURE AND HUMIDITY SENSOR 26

4.3 SOIL MOISTURE (GROVE) 29

4.3.1 RESULT IN DIFFERENT CONDITION 30

CHAPTER 5: CONCLUSION AND FUTURE WORKS 32

$\begin{array}{ll}\text { REFERENCES } & 34\end{array}$

$\begin{array}{ll}\text { APPENDIX } & 35\end{array}$ 


\section{LIST OF FIGURES}

Figure [2.1]: Block diagram of the system 13

Figure [2.2]: Block diagram of Arduino Mega 2560

Figure [2.3]: Block diagram of Relay Module $\quad 15$

Figure [2.4]: Block diagram of LCD Module $\quad 15$

Figure [3.1]: LDR used symbol 17

Figure [3.2]: Resistance VS Illumination 18

Figure [3.3]: DHT11 Temperature and Humidity Sensor 19

Figure [3.4]: Soil Moisture (Grove) 20

Figure [4.1]: Flow chart of the monitoring and control 22

Figure [4.2]: Circuit Diagram of LDR 23

Figure [4.3]: Connection diagram of LDR with Relay Module 24

Figure [4.4]: Arduino Output of LDR (Low Light Condition) 24

Figure [4.5]: Lamp Filament Voltage vs Photoconductive Cell Output 25

Figure [4.6]: Arduino output of DHT11 27

Figure [4.7]: Relay condition for temperature $\quad 27$

Figure [4.8]: Relay condition for humidity $\quad 27$

Figure [4.9]: Circuit diagram of Grove Moisture with Arduino 29

Figure [4.10]: Constructed Circuit of Grove Moisture 29

Figure [4.11]: Arduino Output of Grove Moisture (Humid Condition) 30

Figure [4.12]: Arduino Output of Grove Moisture (Watery Condition) 31

\section{LIST OF TABLES}

Table [4.1]: Light Sensor Readings 25

Table [4.2]: Electrical Characteristics

Table [4.3]: Humidity [DHT11] Readings 28

Table [4.4]: Temperature [DHT11] Readings 28

Table [4.5]: Soil Moisture Sensor Readings 30 
CHAPTER 1: INTRODUCTION 
A greenhouse is an exceptionally outlined homestead structure building to give a more controllable environment to better harvest generation, crop security, product seeding and transplanting. Also, the accessible space of area for developing yields has been altogether diminishing, following to more space of area is vigorously utilized for housing and commercial ventures as a part of this present day period. In most tropical nations, the utilization of greenhouse has been developed for cost effective farming i.e. organic products, new blossoms and vegetables generation. The effectiveness of plant creation inside greenhouse depends fundamentally on the conformity of ideal atmosphere development conditions to attain to high return at low cost, great quality and low natural burden. To attain to these objectives a few parameters, for example, light, temperature and humidity, soil moisture must be controlled ideally given certain criteria through warming, lighting, ventilation and water creation. Persistent checking and controlling of these ecological variables gives significant data relating to the individual impacts of the different elements towards acquiring most extreme harvest creation. Greenhouse situations present remarkable difficulties to great control. Temperature changes happen quickly and fluctuate broadly relying upon sun powered radiation levels, outside temperatures and moistness levels in the greenhouse. Poor light intensity and high stickiness frequently bring about poor natural product set and quality. More exact control can decrease heating fuel and electrical expenses, expand the efficiency of laborers by empowering them to go to more important assignments, empowering directors and producers to settle on better administration choices and invest more energy dealing with the procedure.

Today, programmed control frameworks are the standard for advanced greenhouse, with proceeded with changes as the innovation forces. Environment conditions can be kept up by these programmed control frameworks, where the framework can be worked consequently. The principle parts of any control framework are estimation controller, information preparing, information securing, information presentation and recording. In nature control framework, every parameter must be kept up incessantly inside a certain reach. Be that as it may, no such models yet exist for business greenhouse cultivation. In the agrarian area, particularly creating nations, the use of the earth control innovation is still constrained, basically on account of its high cost. Hence, a supportable improvement of natural observing and control framework for escalated greenhouse generation is inescapable.

In this thesis, we have proposed a framework that can gather the data identified with greenhouse environment and yield status and control the greenhouse consequently in view of the gathered data to foresee and follow up on circumstances for splendidly controlled climatic 
conditions. By thickly observing climatic conditions, this exploration has the reason for making relationship between sensors flags and reference estimations, breaking down the development, advancement of yields and the natural variables to which they are uncovered. Moreover, control programming will give information procurement and control, genuine time graphical show, dates and time labels the data and stores it for present or later utilize. Also, by consistently observing various natural variables without a moment's delay, an agriculturist has the capacity see how development conditions are fluctuating, and respond to those progressions with a specific end goal to expand effectiveness.

\subsection{BACKGROUND AND MOTIVATION}

Bangladesh is an agrarian economy. Agribusiness is the single biggest delivering area of economy since it comprises around $30 \%$ of the nation's GDP and utilizing around $60 \%$ of the labor force. Till now our agricultural systems are followed by conventional method whereas developed countries use automated system to control their agrarian economy to grow more products than before using same lands and weathers, though Moderate weather condition always helps us to grow different plants at different seasons but it does not helping us to escalate crops production without impeding crops from natural destruction. In addition, Dry spells are connected with the late arrival or an early withdrawal of monsoon rains furthermore because of discontinuous droughts agreeing with cultivated phases of different harvests in the north-western and northern areas of Bangladesh. Another downside of climate change is not able to produce a wide range of items like fruits and crops.

So we have considered something which will bring arrangement by presenting some controlled framework that will control the temperature and feed the plants in dry session to deliver yields. If we can utilize mechanized framework in development process, we can produce a wide range of harvests in every season which will chop down import expense and besides work expense will decrease maintenance cost considerably as controlling temperature we keep up immaculate climate for plants.

Moreover, the greenhouse configuration gives light access, and when this light is consumed by items inside the greenhouse and swings to warmth vitality, it is not allowed to get away. The air temperature in the greenhouse will surpass the outside temperature. In the event that it gets excessively hot, all you have, making it impossible to do is open up a portion of the ventilation boards or simply open the entryway, contingent upon the outline and the 
temperature will drop. Greenhouses have the capacity to direct temperatures; temperature variances can push plants and moderate development. The impenetrable covering on a greenhouse makes it get to be very hot and moist inside amid the daylight. The dampness vanishing from the dirt, and the dampness given off by photosynthesizing plants fills the air. When the air is extremely damp, it gets to be harder for plants to lose water through vanishing, and moreover with the dirt. This serves to continue everything from drying out on a hot sunny day. Subsequently, it is vital to have air course to fumes over the top moistness and control air trade.

In a nutshell we believe our project will bring the change to our conventional agricultural. It is nothing but a small initiative of a huge upcoming success of our agricultural and scientific sector.

\subsection{DESCRIPTION}

This is a multifaceted set up which is very much prepared to respond to the vast majority of the climatic changes happening inside the greenhouse. It chips away at an input framework which helps it to react to the outside blows proficiently. In spite of the fact, this set-up overcomes the issues created because of human errors it is not totally mechanized and wasteful.

The proposed framework is an implanted framework which will nearly screen and control the small scale climatic parameters of a greenhouse on a usual premise. For the development of products or particular plant species which could enhance their creation over the entire yield development season and to kill the challenges included in the framework by falling human negotiation to the best feasible degree. The framework contains sensors, Arduino which is helping us the use of micro controller easily and actuators (Relay module).

At the point when any of the above-mentioned climatic parameters cross a security limit which has to be kept up to secure the yields, the sensors sense the change and the micro controller reads this from the information at its data ports in the wake of being changed over to an advanced frame by the ADC. The micro controller then performs the required activities by utilizing transfers until the strayed-out parameter has been taken back to its ideal level. Since a micro controller is utilized as the heart of the framework, it makes the set-up minimal effort and compelling all things considered. As the framework likewise utilizes a LCD show for constantly alarming the client about the condition inside the greenhouse, the whole set-up gets to be easy to use. 
Consequently, this system reduces the drawbacks of the prevailing set-ups mentioned in the preceding segment and is designed as an easy to retain, flexible and low cost resolution.

\subsection{OBJECTIVE OF THE PROJECT}

We live in our current reality where everything can be controlled and worked naturally, however there are still a couple of vital segments in our nation where computerization has not been received or not been put to an incontestable utilization, maybe in dainty of a few reasons one such reason is expense. One such field is that of agricultural. Agricultural has been one of the essential occupations of man subsequent to right on time developments and even today manual interventions in cultivating are certain. Greenhouse frame an imperative piece of the agribusiness and agriculture areas in our nation as they can be utilized to develop plants under controlled climatic conditions for ideal produce. An automated system inside a greenhouse visualizes checking and controlling of the climatic parameters which specifically or in an indirect way administer the plant development and consequently their produce. Automation is methodology control of automated hardware and courses of action, subsequently supplanting human proprietors.

\subsection{OUTLINE OF THE PAPER}

The paper expresses to the structure which is an automated framework, monitoring and control inside greenhouse.

Section 2 is about the summation of the entire setup in the project where the piece outline, pictures and the usage of the setup is clarified.

In Chapter 3 explanation of the different kind of sensors is given and also a brief of the methodology we utilized all through the task is explained.

All our test outcomes, charts and examination are given in part 4. In part 5 the conclusion and future works are depicted which additionally incorporates our prosperity and in addition obliges and bottlenecks of this project in point of interest. 
CHAPTER 2: OVERVIEW OF THE PROJECT AND SETUP 


\subsection{SYSTEM OVERVIEW}

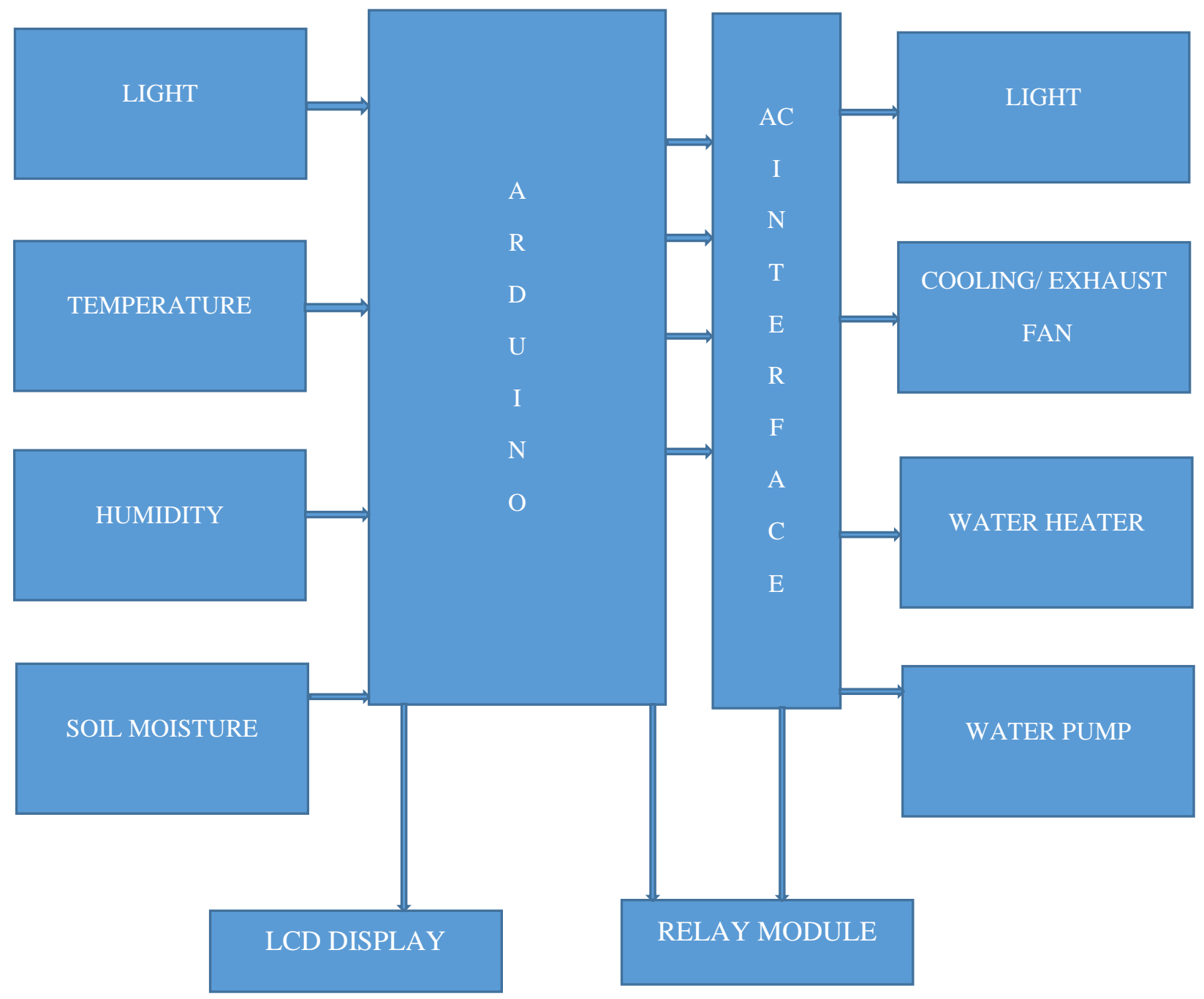

Figure [2.1]: Block diagram of the system

\subsection{COMPONENTS}

- Sensors

- $\quad$ LDR (Light dependent resistor)

- $\quad$ Temperature and Humidity Sensor (DHT11)

- $\quad$ Soil Moisture Sensor (Grove Moisture)

- Arduino Mega 2560

- LCD Display

- 4 channel 5V Relay Module 
- $\mathrm{AC} \& \mathrm{DC}$ source

- Devices Controlled

- Water pump

- Cooling and exhaust fan

- Artificial light

- Water Heater

\subsubsection{ARDUINO}

Arduino is a situated of advancement sheets that accompany pretested equipment and programming libraries. That is to say, easy to Arduino board and begin adding to your task immediately. The sheets are constructed around the AVR microcontroller as the base. Programming libraries to run on the board are composed and made accessible free of charge.

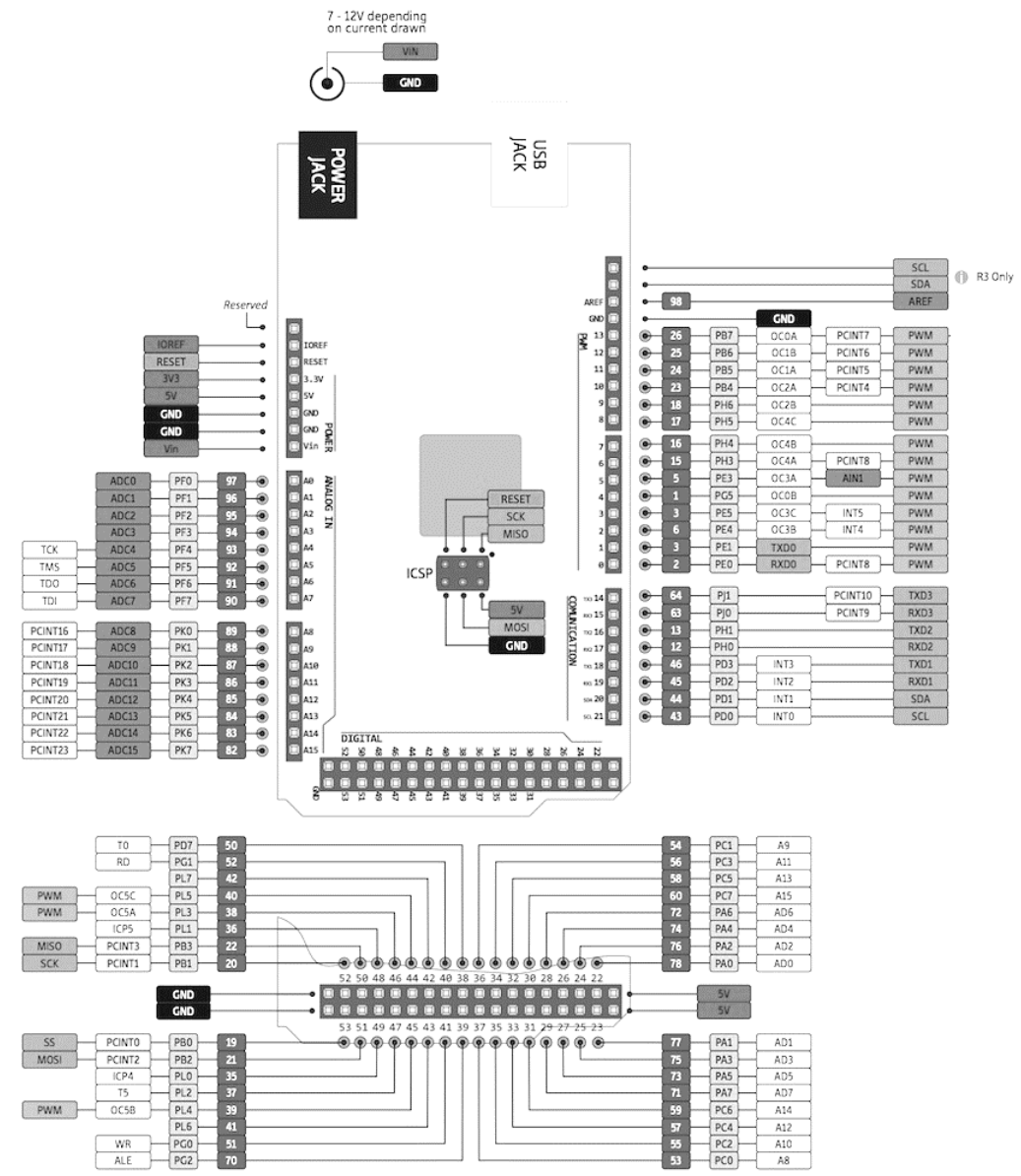

Figure [2.2]: Block diagram of Arduino Mega 2560 


\subsubsection{RELAY MODULE}

A cluster of actuators can be utilized as a part of the framework. For example, transfers, contactors, and change over switches and so forth. They are utilized to turn on AC devices. For example, engines, coolers, pumps, haze machines, sprayers. With the end goal of exhibit transfers have been utilized to drive AC globules to reproduce actuators and AC gadgets. A complete working framework can be acknowledged by essentially replacing these simulation devices by the actual devices.

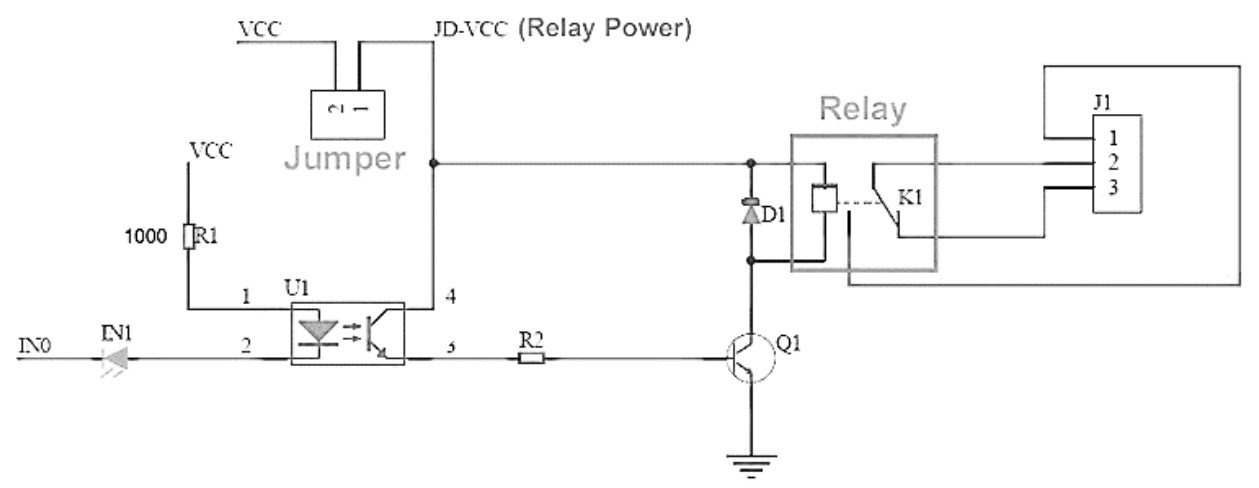

Figure [2.3]: Block diagram of Relay Module

\subsubsection{LCD}

A Liquid crystal display is used to indicate the present status of parameters and the respective AC devises (simulated using bulbs). The information is displayed in two modes which can be selected using a push button switch which toggles between the modes. Any display can be interfaced to the system with respective changes in driver circuitry and code.

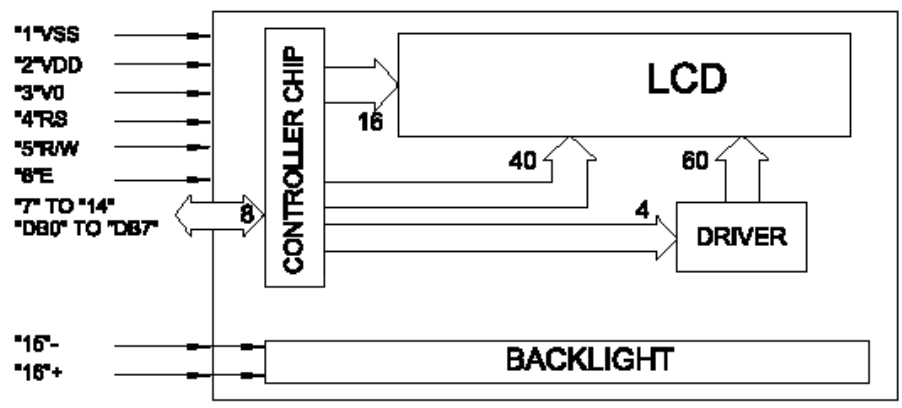

Figure [2.4]: Block diagram of LCD Module 
CHAPTER 3: SENSORS 


\section{$3.1 \quad L D R$}

A Light Dependent Resistor (LDR) or a photo resistor is a device whose resistivity is a function of the incident electromagnetic radiation. Hence, they are light sensitive devices. They are also called as photo conductors, photo conductive cells or simply photocells. They are made up of semiconductor materials having high resistance. There are many different symbols used to indicate a LDR, one of the most commonly used symbol is shown in the figure below. The arrow indicates light falling on it.

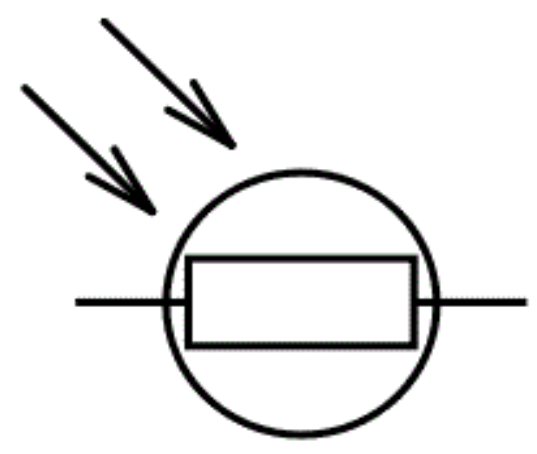

Figure [3.1]: LDR used symbol

A light ward resistor deals with the guideline of photo conductivity. Photo conductivity is an optical perception in which the materials conductivity (Hence resistivity) decreases when light is consumed by the material.

At the point when light falls i.e. at the point when the photons fall on the gadget, the electrons in the valence band of the semiconductor material are eager to the conduction band. These photons in the episode light should to have energy more prominent than the band hole of the semiconductor material to make the electrons hop from the valence band to the conduction band. Consequently when light sufficiently having vitality is episode on the gadget more \& more electrons are eager to the conduction band which brings about expansive number of charge bearers. The aftereffect of this methodology is more present begins streaming and thus it is said that the resistance of the gadget has diminished. This is the most well-known working standard of LDR. [6] 
LDR's are light subordinate devices whose resistance diminishes when light falls on them and increments oblivious. At the point when a light ward resistor is kept in dull, its resistance is high. This resistance is called as dull resistance. It can be as high as $1012 \Omega$. What's more, if the implement is permitted to retain light its resistance will diminish radically. In the event that a consistent voltage is connected to it and force of light is expanded the current begins expanding.

Figure below shows resistance vs. illumination curve for a particular LDR.

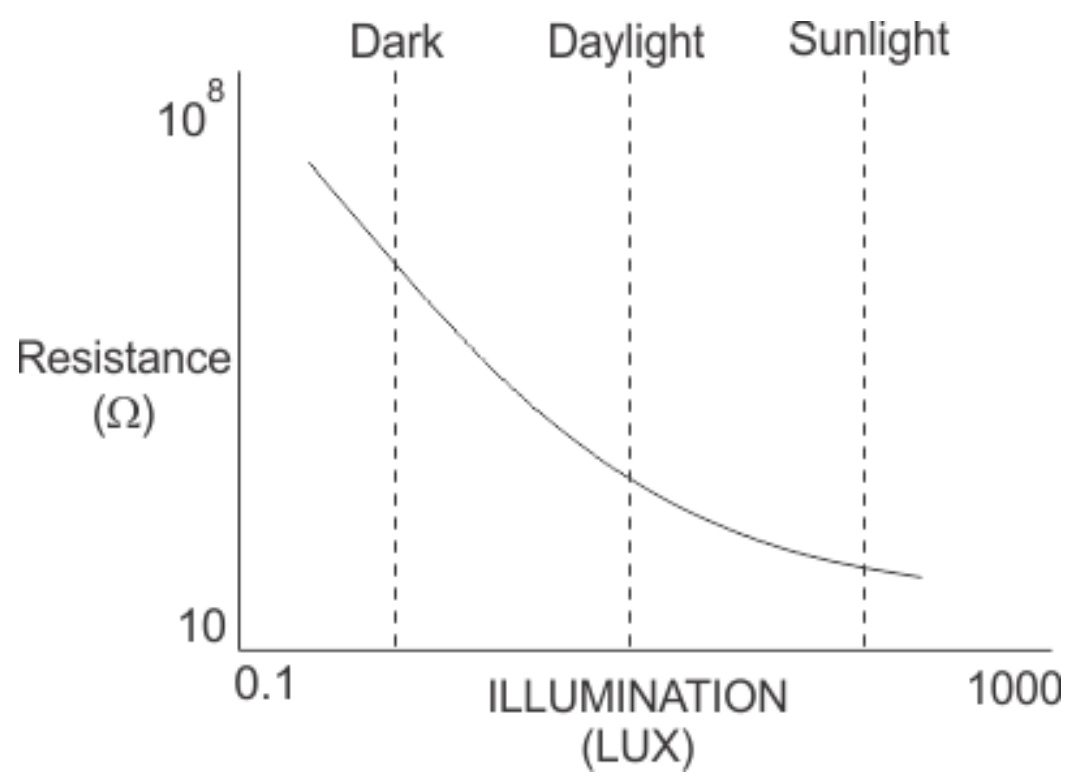

Figure [3.2]: Resistance $V_{S}$ Illumination

LDR's have minimal effort and straightforward structure. They are frequently utilized as light sensors. They are utilized when there is a need to recognize absences or habitations of light like in a cam light meter. Used in street lamps, alarm clock, burglar alarm circuits, light intensity meters, for counting the packages moving on a conveyor belt, etc.

\subsection{DHT-11 TEMPERATURE AND HUMIDITY SENSOR}

DHT11 Temperature \& Humidity Sensor highlights a temperature \& stickiness sensor complex with a calibrated digital signal input. By utilizing the selective computerized sign securing system and temperature \& dampness sensing innovation, it ensures high reliability and 
excellent long-term stability. This sensor incorporates a resistive-sort moistness estimation segment and a NTC temperature estimation part, and associate with a high- execution 8-bit microcontroller, offering fabulous quality, quick reaction, hostile to obstruction capacity and expense adequacy. [9]
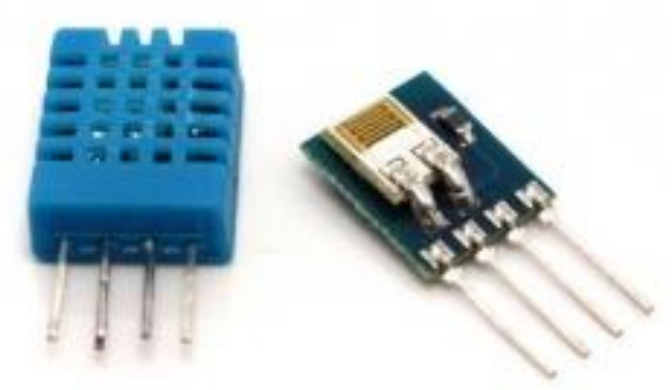

Figure [3.3]: DHT11 Temperature and Humidity Sensor

Each DHT11 component will be entirely balanced in the lab that will be to a great degree exact on dampness adjustment. The adjustment coefficients are put away as projects in the OTP memory, which are utilized by the sensor's inner sign distinguishing methodology. The single-wire serial interface makes framework reconciliation brisk and simple. Its little size, low power utilization and up-to-20 meter signal transmission settling on it the best decision for different applications, including those most requesting ones. The part is 3-pin single line pin bundle. It is advantageous to associate and unique bundles can be given in response to popular demand.

\subsubsection{TECHNIAL SPECIFICATION}

$\begin{array}{ll}\text { Measurement Range } & 20-90 \% \mathrm{RH} \quad 0-50^{\circ} \mathrm{C} \\ \text { Humidity Accuracy } & \pm 5 \% \mathrm{RH} \\ \text { Temperature Accuracy } & \pm 2{ }^{\circ} \mathrm{C} \\ \text { Resolution } & 1 \\ \text { Package } & 3 \text { Pin Single Row }\end{array}$


Applying the DHT11 sensor past its working reach expressed in this datasheet can bring about 3\% RH sign movement/error. The DHT11 sensor can improve to the aligned status bit by bit when it returns to the typical working condition and works inside its range. If it's not too much trouble make an effort to remain mindful that working the DHT11 sensor in the non-typical working conditions will quicken sensor's maturing procedure.

Relative humidity to a great extent relies on upon temperature. In spite of the fact that temperature compensation innovation is utilized to guarantee exact estimation of RH, it is still unequivocally encouraged to keep the dampness and temperature sensors working under the same temperature. DHT11 should to be mounted at the spot quite far from parts that may create heat. Long time presentation to solid daylight and bright may spoil DHT's execution.

\subsection{GROVE SOIL MOISTURE}

This Moisture Sensor can be utilized to recognize the dampness of soil or judge if there is water around the sensor, let the plants inside greenhouse connect for human help. They can be exceptionally to utilize, simply embed it into the dirt and after that read it. With help of this sensor, it will be feasible to make the plant remind: thirsty now, need some water. [11]

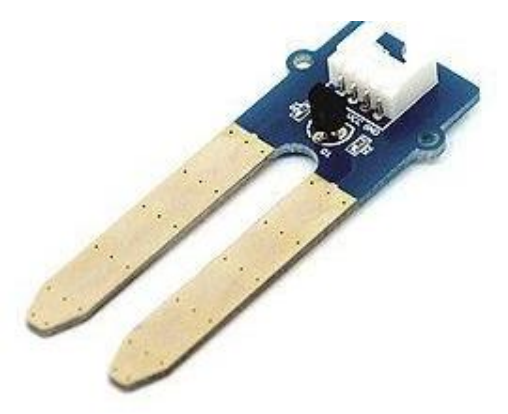

Figure [3.4]: Soil Moisture (Grove)

\subsubsection{FEATURES}

i. Easy to use

ii. $\quad 2.0 \mathrm{~cm} * 6.0 \mathrm{~cm}$ grove module 
CHAPTER 4: TEST RESULTS AND ANALYSIS 
It is essential to effectively recognize the parameters that will be measured by the controller's information procurement interface, and how they are to be measured.

An imperative component in considering a control framework is the control technique that is to be taken after. The most straightforward procedure is to utilize edge sensors that straightforwardly influence incitation of gadgets. For case, the temperature inside a greenhouse can be influenced by controlling warmers, fans, or window openings once it surpasses the most extreme permissible farthest point. The light force can be controlled utilizing four edge levels. As the light power diminishes one light may be turned on. With a further decline in its force a second light would be controlled, et cetera; accordingly guaranteeing that the plants are not denied of sufficient daylight apart within the winter season or an overcast day.

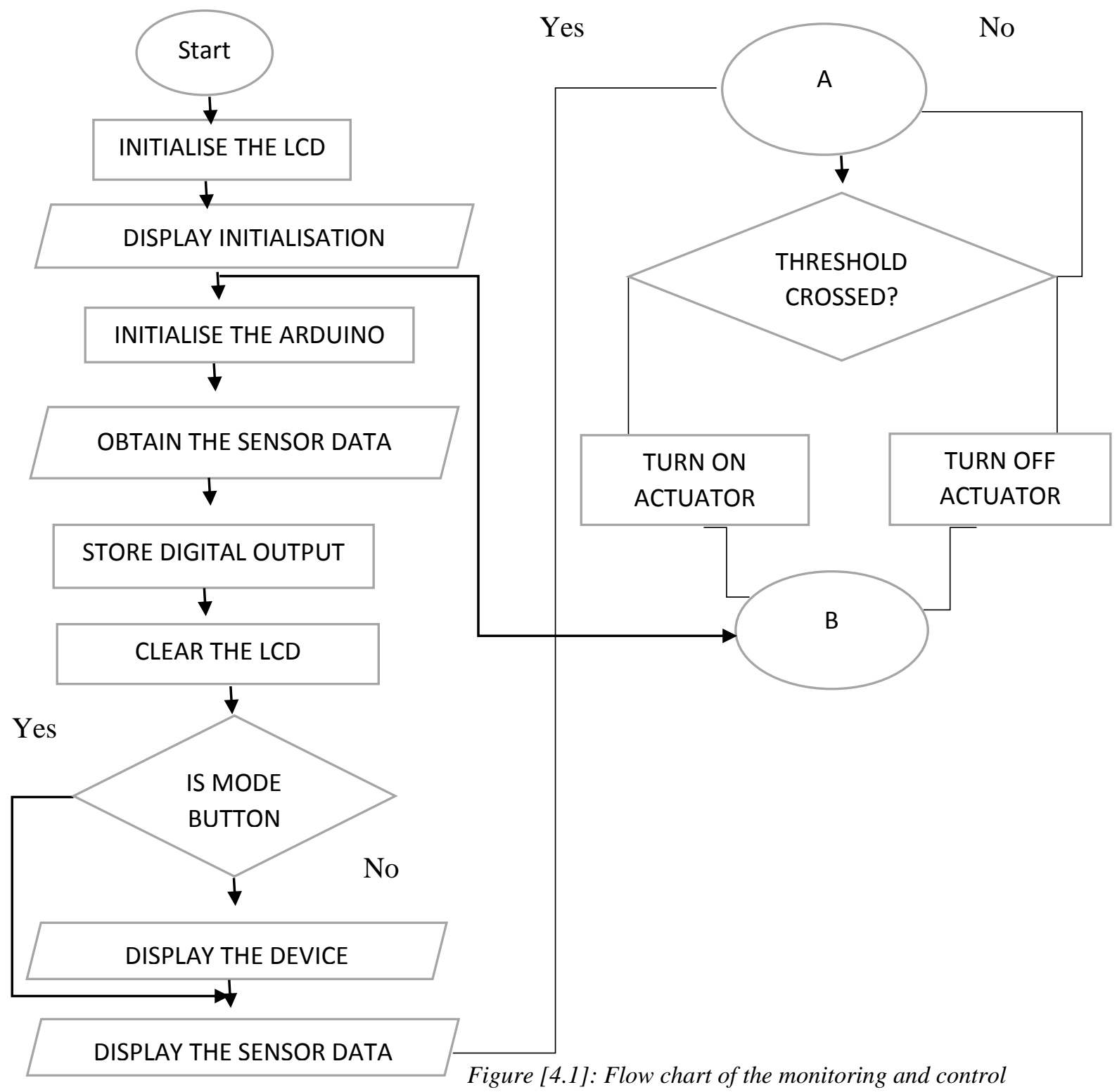




\subsection{LIGHT SENSITIVITY (LIGHT SENSOR USING ARDUINO)}

A LDR and an ordinary resistor are wired in arrangement over a voltage, as demonstrated in the circuit below. Depending upon which is attached to the $5 \mathrm{~V}$ and which to $0 \mathrm{~V}$, the voltage at the point between them, call it the sensor hub, will either rise or fall with expanding light. On the off chance that the LDR is the part fixing straightforwardly to the $5 \mathrm{~V}$, the sensor hub will increment in voltage with expanding light.

The LDR's resistance can achieve $10 \mathrm{k}$ ohms in dull conditions and around $100 \mathrm{ohms}$ in full brilliance.

The circuit used for sensing light in our system uses a $10 \mathrm{k} \Omega$ fixed resistor which is tied to $+5 \mathrm{~V}$. Hence the voltage value in this case decreases with increase in light intensity.

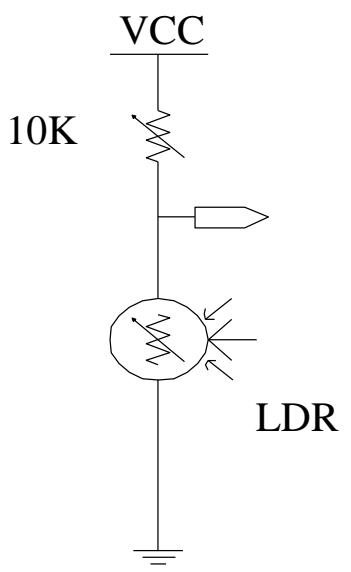

Figure [4.2]: Circuit Diagram of LDR

The relationship between the resistance RL and light power Lux for a regular LDR is:

$$
\mathrm{RL}=500 / \operatorname{Lux} \mathrm{k} \Omega
$$

With the LDR connected to $5 \mathrm{~V}$ through a $10 \mathrm{~K}$ resistor, the output voltage of the LDR is:

$$
\mathrm{Vo}=5 * \mathrm{RL} /(\mathrm{RL}+10)
$$


With a specific end goal to build the affectability of the sensor we must diminish the estimation of the settled resistor in arrangement with the sensor. This may be finished by putting different resistors in parallel with it.

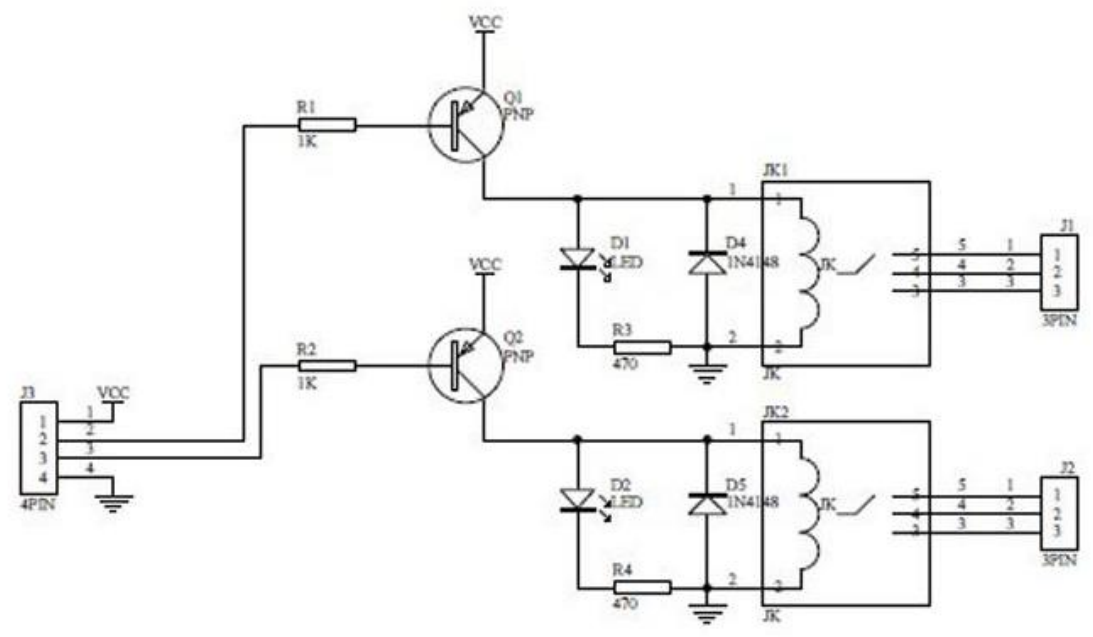

Figure [4.3]: Connection diagram of LDR with Relay Module

The sensor hub voltage is contrasted and the limit voltages for unique levels of light power comparing to the four conditions- Optimum, Dim, Dark and Night.

\subsubsection{MONITORING}

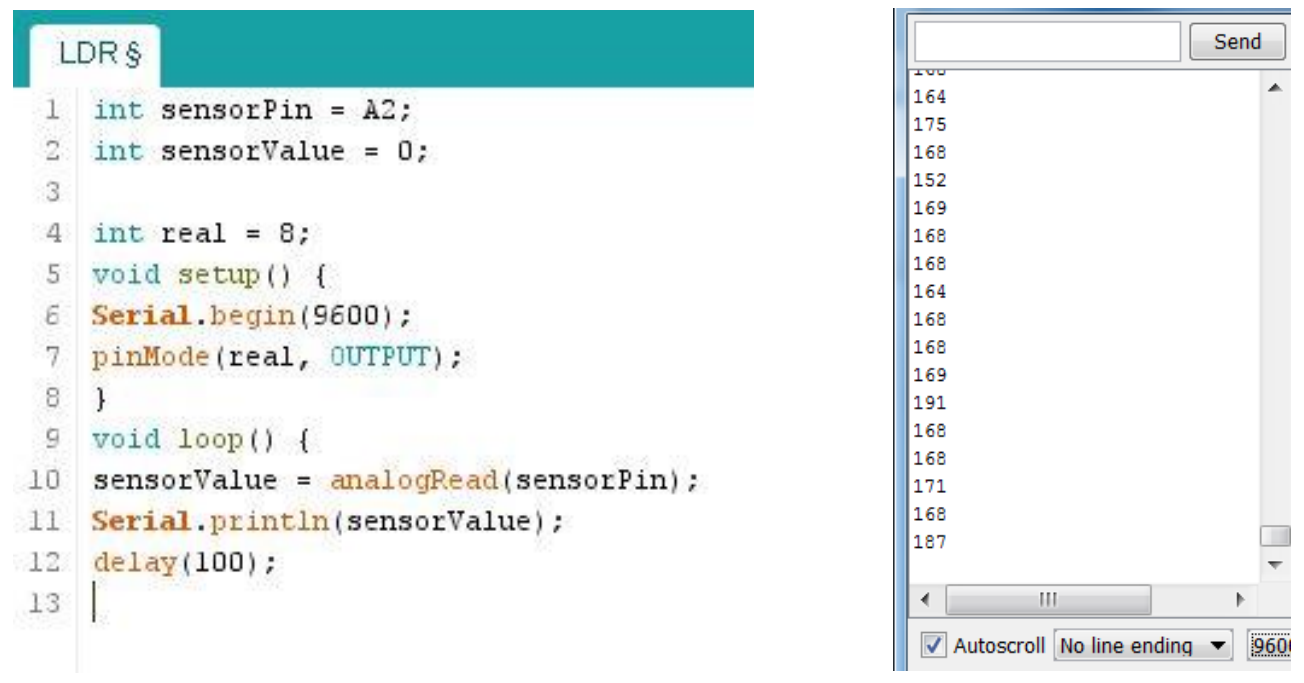

Figure [4.4]: Arduino Output of LDR (Low Light Condition) 


\begin{tabular}{|l|l|}
\hline Illumination Status & Transducer Optimum Range \\
\hline Optimum Illumination & $0 \mathrm{~V}-0.69 \mathrm{~V}$ \\
\hline Dim Light & $0.7 \mathrm{~V}-2.5 \mathrm{~V}$ \\
\hline Dark & $2.5 \mathrm{~V}-3 \mathrm{~V}$ \\
\hline Night & $3 \mathrm{~V}-3.47 \mathrm{~V}$ \\
\hline
\end{tabular}

Table [4.1]: Light Sensor Readings

\subsubsection{CONTROL}

Here we can see the condition for dim light situation is $0.7 \mathrm{~V}-2.5 \mathrm{~V}$; when light intensity 500 lumen. That means there is presence of light. If the light intensity is below than 500 then our automated system detects it and turn ON the relay module. The artifical light will shine untill the sunrises. If there is any existance of cloudy weather or rainy our automated system will work if the intensity of the light does not match with the unit one.

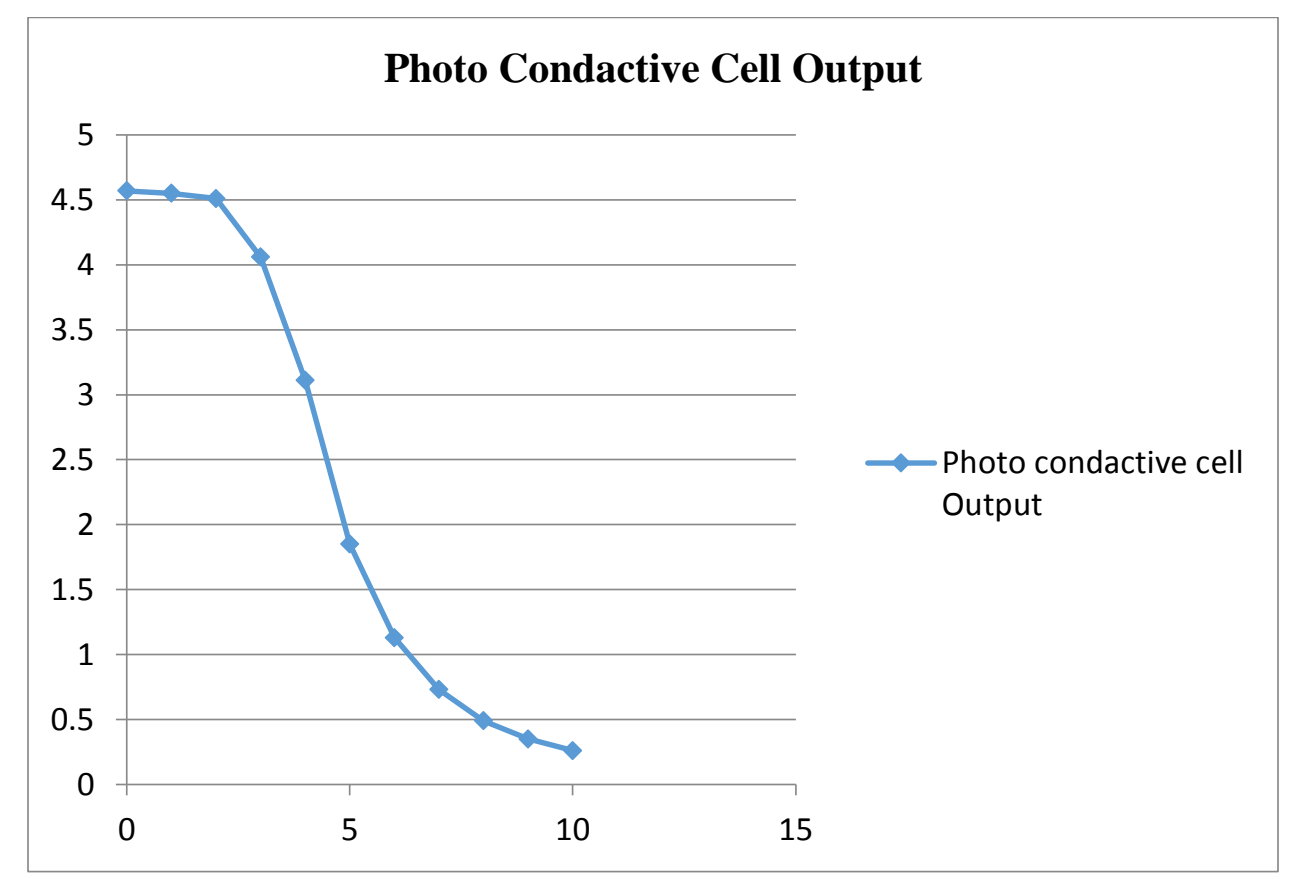

Figure [4.5]: Lamp Filament Voltage vs Photoconductive Cell Output 


\subsection{DHT11 TEMPERATURE AND HUMIDITY SENSOR}

The sensor builds up a direct voltage versus $\mathrm{RH}$ yield that is ratio metric to the supply voltage. That is, the point at which the supply voltage fluctuates, the sensor yield voltage follows in the same extent. It can work over a 4-5.8 supply voltage range. At 5V supply voltage, and room temperature, the yield voltage ranges from 0.8 to $3.9 \mathrm{~V}$ as the mugginess changes from $0 \%$ to $100 \%$ (noncondensing).

The output voltage is converted to temperature by a simple conversion factor. The general equation used to convert output voltage to temperature is:

$$
\text { Temperature }\left({ }^{\mathrm{O}} \mathrm{C}\right)=\left(\mathrm{V}_{\text {out }} * 100\right) / 5{ }^{\mathrm{o}} \mathrm{C}
$$

Sensor output voltages be taken into account according to the formula:

$$
\mathrm{RH}=((\text { Vout } / \text { Vsupply })-0.16) / 0.0062 \text {, typical at } 25^{\circ} \mathrm{C}
$$

\begin{tabular}{|l|l|l|l|l|}
\hline & Condition & Minimum & Typical & Maximum \\
\hline Power Supply & DC & $3 \mathrm{~V}$ & $5 \mathrm{~V}$ & $5.5 \mathrm{~V}$ \\
\hline Current Supply & Measuring & $0.5 \mathrm{~mA}$ & & $2.5 \mathrm{~mA}$ \\
\hline & Average & $0.2 \mathrm{~mA}$ & \\
\cline { 2 - 3 } & Standby & $100 \mathrm{uA}$ & & $150 \mathrm{uA}$ \\
\hline Sampling Period & Second & 1 & & \\
\hline
\end{tabular}




\subsubsection{DHTII SENSOR USING ARDUINO}

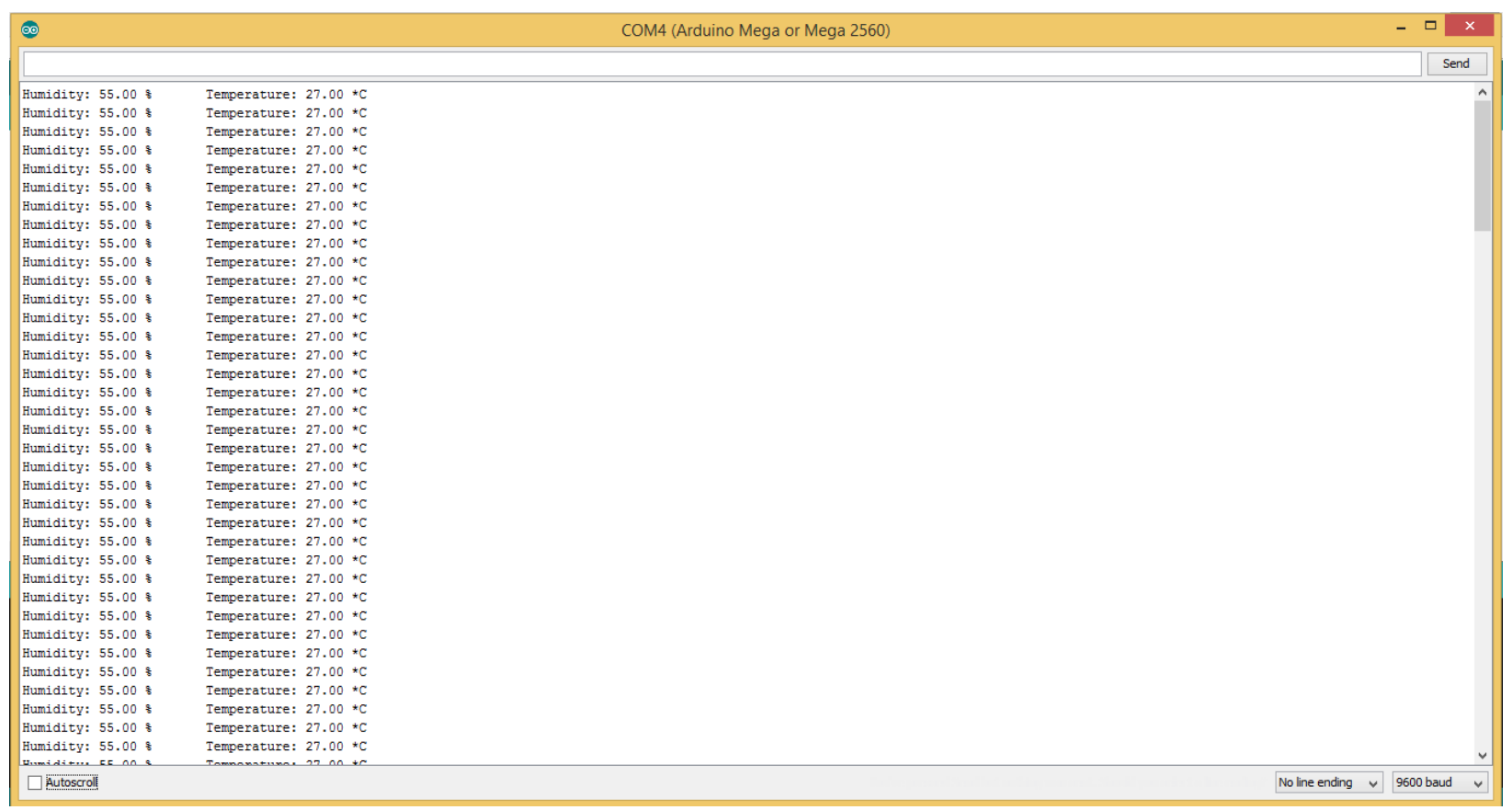

Figure [4.6]: Arduino output of DHT11

\subsubsection{CONTROLING STRUCTURE}

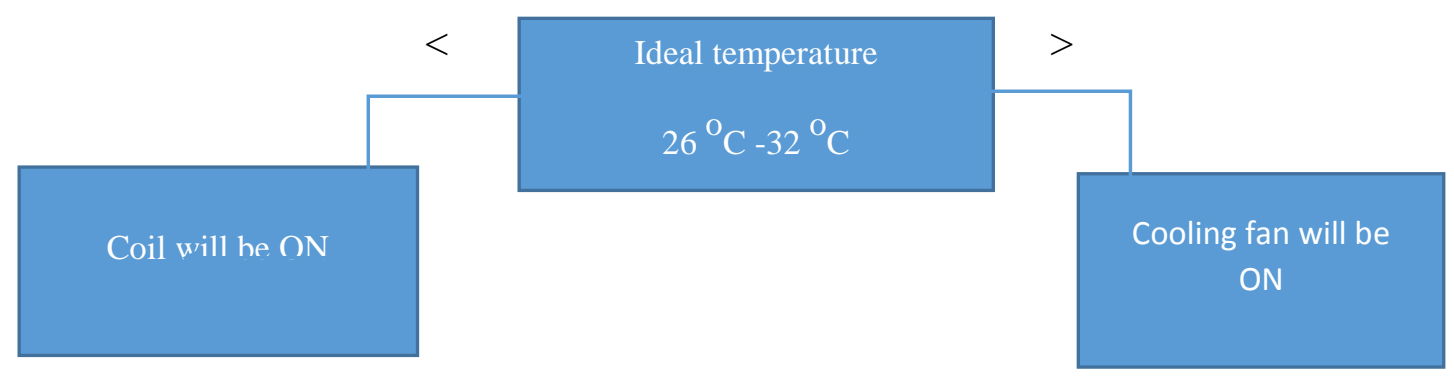

Figure [4.7]: Relay condition for temperature

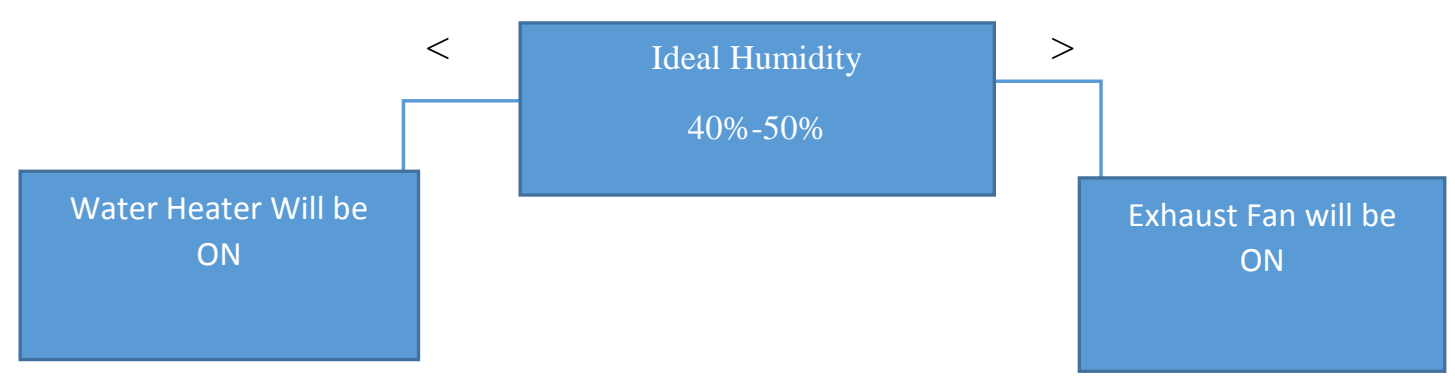

Figure [4.8]: Relay condition for humidity 
Exhaust fans can move a substantial volume of the hot plant sales outlet freshen up and pull outside air in through the back vent. They're intense for a reason, as full sun on a hot summer day can bring about temperatures inside the nursery to superheat. A fumes fan must have the capacity to drag this freshen up, or the temperatures will keep on rising.

Overhead infrared warming gear joined with soil link warmth gives a limited plant environment, which permits plants to flourish despite the fact that the encompassing air is at a lower than typical temperature. Electric resistance-sort warmers are utilized as space radiators or as a part of a constrained air framework.

\begin{tabular}{|c|c|}
\hline Relative Humidity & Transducer Optimum Range \\
\hline $30.8 \%$ to $40.5 \%$ & $1.75-2.05 \mathrm{~V}$ \\
\hline $41.3 \%$ to $50.3 \%$ & $2.075-2.35 \mathrm{~V}$ \\
\hline $51 \%$ to $60.02 \%$ & $2.375-2.65$ \\
\hline $61.6 \%$ to $70.5 \%$ & $2.7-2.975 \mathrm{~V}$ \\
\hline
\end{tabular}

Table [4.3]: Humidity [DHT11] Readings

\begin{tabular}{|c|c|}
\hline Temperature range & Sensor output( $\left.\mathbf{V}_{\text {out }}\right)$ \\
\hline $20^{\circ}$ to $25^{\circ} \mathrm{C}$ & $1.0-1.25 \mathrm{~V}$ \\
\hline $25^{0}$ to $30^{\circ} \mathrm{C}$ & $1.25-1.5 \mathrm{~V}$ \\
\hline $30^{\circ}$ to $35^{\circ} \mathrm{C}$ & $1.5-1.75 \mathrm{~V}$ \\
\hline $35^{\circ}$ to $40^{\circ} \mathrm{C}$ & $1.75-2.0 \mathrm{~V}$ \\
\hline
\end{tabular}

Table [4.4]: Temperature [DHT11] Readings

\subsection{SOIL MOISTURE (GROVE)}

The elementary idea behind using soil moisture sensor to control irrigation is simple: when plants use water, they take it up from the substrate, so the water content of the substrate decreases. Soil water sensors detect these changes and can be used to open an irrigation valve when the substrate water content drops below a user-determined set-point. This results in frequent applications of small amounts of water, and the frequency of irrigation is adjusted automatically based on the rate 
of substrate water depletion. This irrigation approach automatically replaces water that is used by plants or lost through evaporation and assures that plants are never exposed to drought stress. By irrigating with the amount of water actually needed by the plants, water use and leaching can be reduced greatly. This minimizes pollution without using expensive recycling irrigation systems or large ponds to capture runoff.

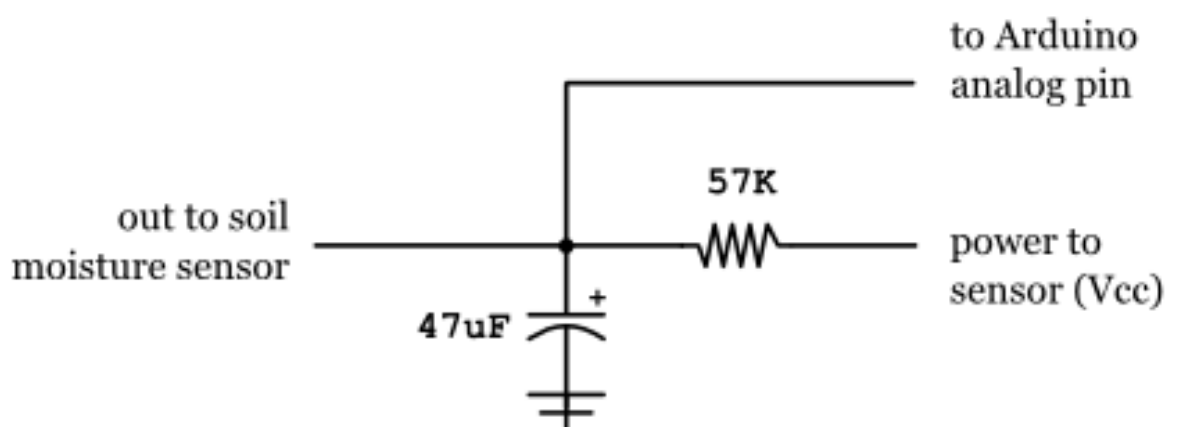

Figure [4.9]: Circuit diagram of Grove Moisture with Arduino

Soil condition is very important for plants for a great output. As far as we can see moisture of soil is depending on the water level of the soil. So in this paper we prefer a soil moisture sensor to sense the condition of soil whether it is dry, humid or watery. If the soil condition is dry it is automatically on the servo to on the water supply. When the soil becomes humid it will close the water supply automatically.

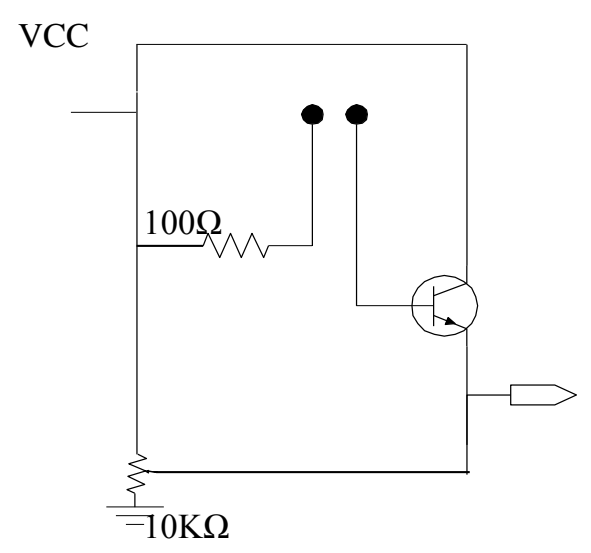

Figure [4.10]: Constructed Circuit of Grove Moisture 


\begin{tabular}{|l|l|}
\hline Soil Condition & Transducer Optimum Range \\
\hline Dry & $0 \mathrm{~V}$ \\
\hline Optimum Level & $1.9-3.5 \mathrm{~V}$ \\
\hline Slurry Soil & $>3.5 \mathrm{~V}$ \\
\hline
\end{tabular}

Table [4.5]: Soil Moisture Sensor Readings

\subsubsection{RESULT IN DIFFERENT CONDITION}

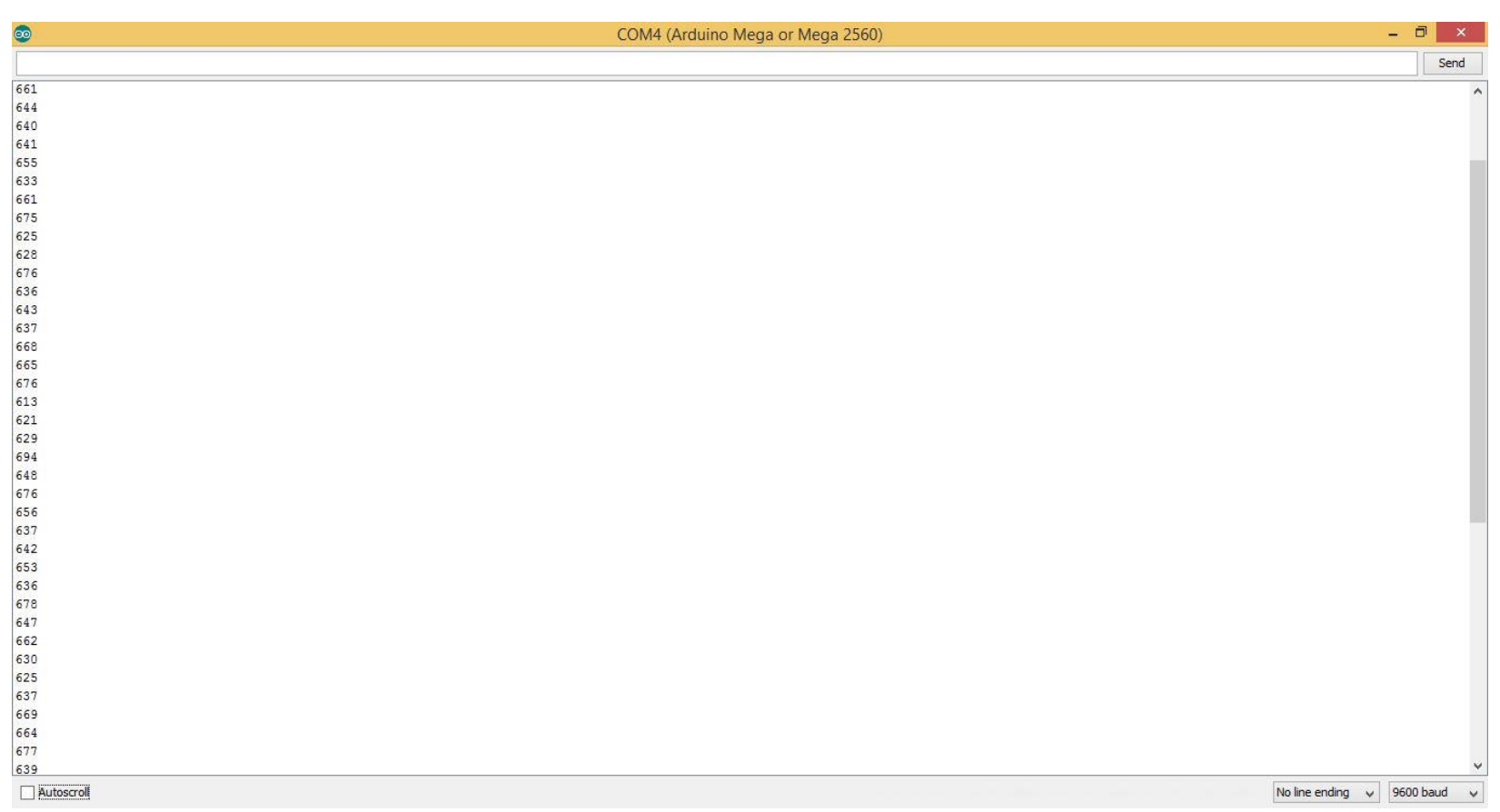

Figure [4.11]: Arduino Output of Grove Moisture (Humid Condition) 


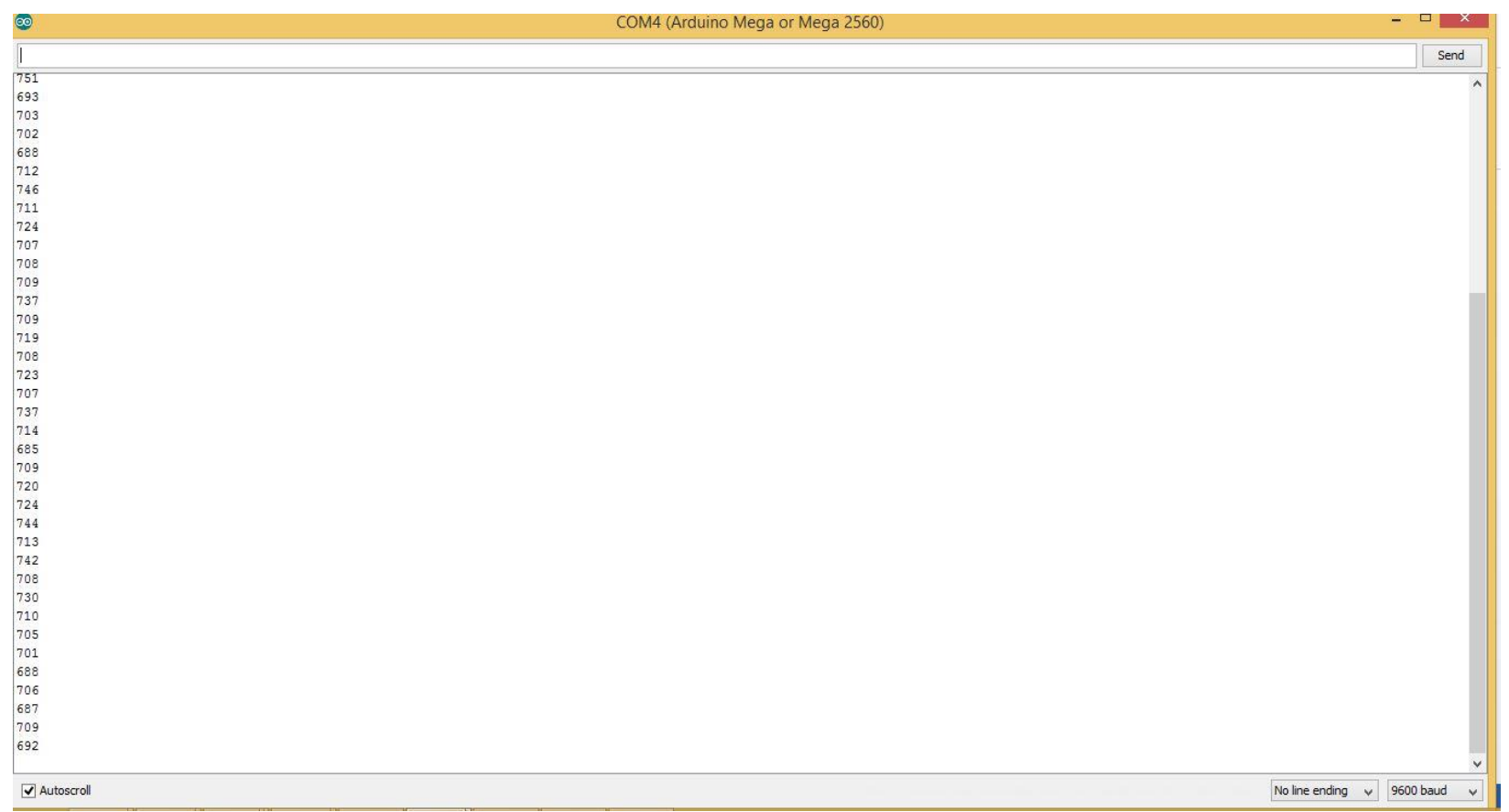

Figure [4.12]: Arduino Output of Grove Moisture (Watery Condition) 


\section{CHAPTER 5: CONCLUSION AND FUTURE WORKS}


It is our great pleasure that we have successfully completed our project which we dreamed of previously. In addition, we want to build a wireless remote control system with more parameters such as $\mathrm{CO} 2, \mathrm{pH}$ factor detection etc.

To be confirmed, we have tasted our greenhouse project in different places whether it works without any error or not and we delighted to get positive feedback regarding our project implemented in Botanical Garden. In addition, Botanical Garden authority showed their huge interest to assist us in every aspect for our further research, which is a massive opportunity for us to move forward.

The framework has effectively overcome very a few inadequacies of the existing frameworks by lessening the force utilization, upkeep and intricacy, in the meantime giving an adaptable and exact manifestation of keeping up nature. Moreover, the consistently diminishing expenses of equipment and programming, the more extensive acknowledgement of electronic frameworks in agribusiness, and a developing farming control framework industry in a few ranges of horticultural creation, will result in dependable control frameworks that will address a few parts of value and amount of generation. Further changes will be made as less costly and more solid sensors are created for utilization in horticultural creation.

Despite the fact that the improvements said in the past part may appear to be far later on, the obliged innovation and segments are accessible, numerous such frameworks have been autonomously created, or are in any event tried at a model level. Additionally, combination of all these advancements is not an overwhelming errand and can be effectively completed. 


\section{References}

1. Quan Minh Vu, "Automated Wireless Greenhouse Management System", Master of Engineering in Electronics and Computer Systems, Massy University, Palmerston North, New Zealand, June 2011

2. Jose Luis Guzman, "Simulation of Greenhouse Climate Monitoring and Control with Wireless Sensor Network and Event-based Control”, Department of Computer Science and Automatic Control, UNED C/. Juan Del Rosal, Madrid, Spain

3. Masayu Binti Hussein, "Automatic Greenhouse Watering System Using Microcontroller" University Malaysia Pahang

4. David Whiting (CSU Extension, retired) with Michael Roll and Larry Vickerman (former CSU Extension employees). Artwork by Scott Johnson and David Whiting

5. Md. Anisul Hoque, “Greenhouse Effect”, Leominster Road, London, UK, The Daily Star

6. http://www.gpnmag.com/greenhouse-light

7. http://www.ag.auburn.edu/hort/landscape/lightintensityquality.html

8. http://www.electronics-tutorials.ws/io/io_4.html

9. By Anthony J. De Blasi "Greenhouse Growing: Tips for Basic Greenhouse Cultivation" Mother Earth News

10. "Light and Lighting Control in Greenhouse", Argus Control System Limited, White Rock, Canada

11. http://www.robotshop.com/media/files/pdf/grove-moisture-sensor-sen92355p.pdf 


\title{
Appendix
}

\section{Arduino Code for monitoring and control with Relay Module}

\author{
\#include "DHT.h" \\ \#include <LiquidCrystal.h> \\ \#include <Servo.h> \\ Servo myservo; \\ int $\operatorname{pos}=0$; \\ \#define DHTPIN 22 \\ \#define DHTTYPE DHT11 \\ \#define RELAY_ON 0 \\ \#define RELAY_OFF 1 \\ \#define Relay_1 24 \\ \#define Relay_2 26 \\ \#define Relay_3 28 \\ \#define Relay_4 30 \\ \#define Relay_5 32
}

DHT dht(DHTPIN, DHTTYPE);

LiquidCrystal lcd(12, 11, 5, 4, 3, 2);

int $\mathrm{LDR}=2$;

int LDRValue $=0$; 


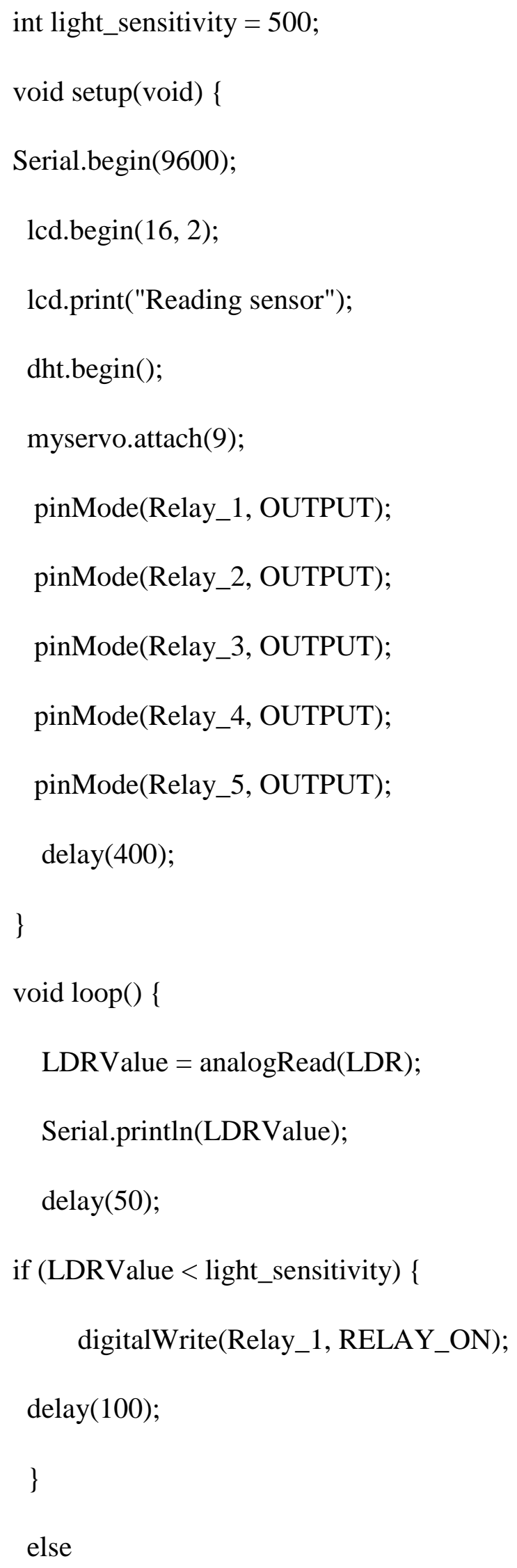


digitalWrite(Relay_1, RELAY_OFF);

delay(400);

\}

float temperature, humidity;

humidity $=$ dht.readHumidity () ;

temperature $=$ dht.readTemperature () ;

$\operatorname{delay}(200)$;

lcd.clear();

char tempF[6];

char humF[6];

dtostrf(temperature, 5, 1, tempF);

dtostrf(humidity, 2, 0, humF);

lcd.print("T:");

lcd.print(tempF);

lcd.print((char)223);

lcd.print("C ");

lcd.print("H: ");

lcd.print(humF);

lcd.print("\%");

if (temperature < 22) \{

digitalWrite(Relay_2, RELAY_ON);

$\operatorname{delay}(100)$; 


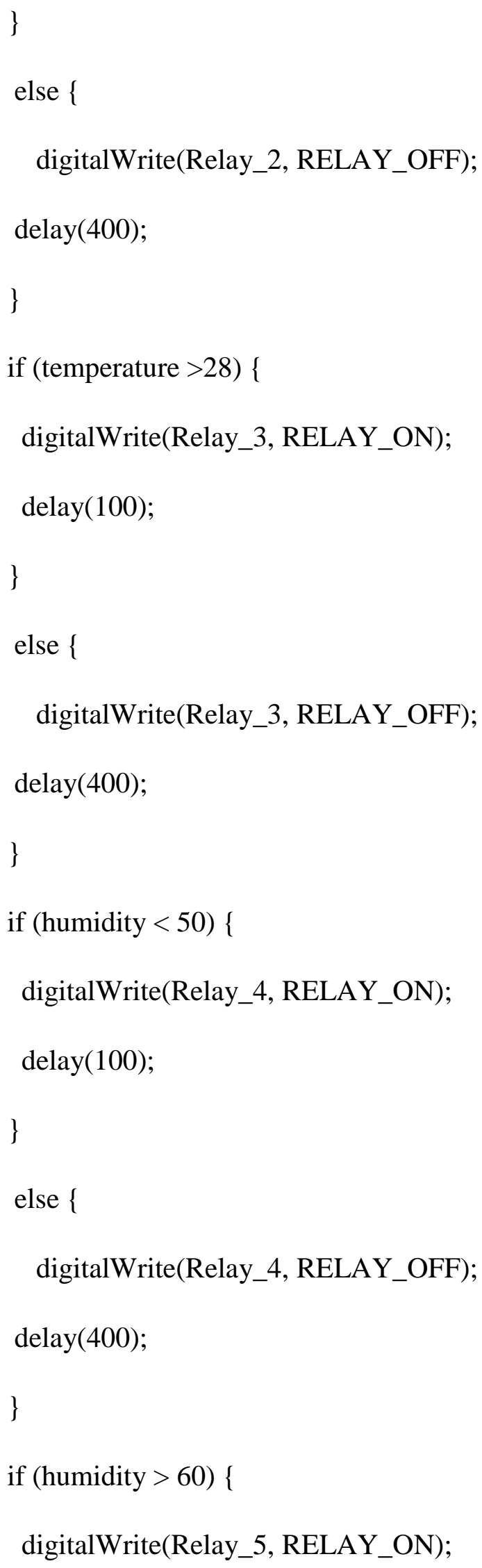




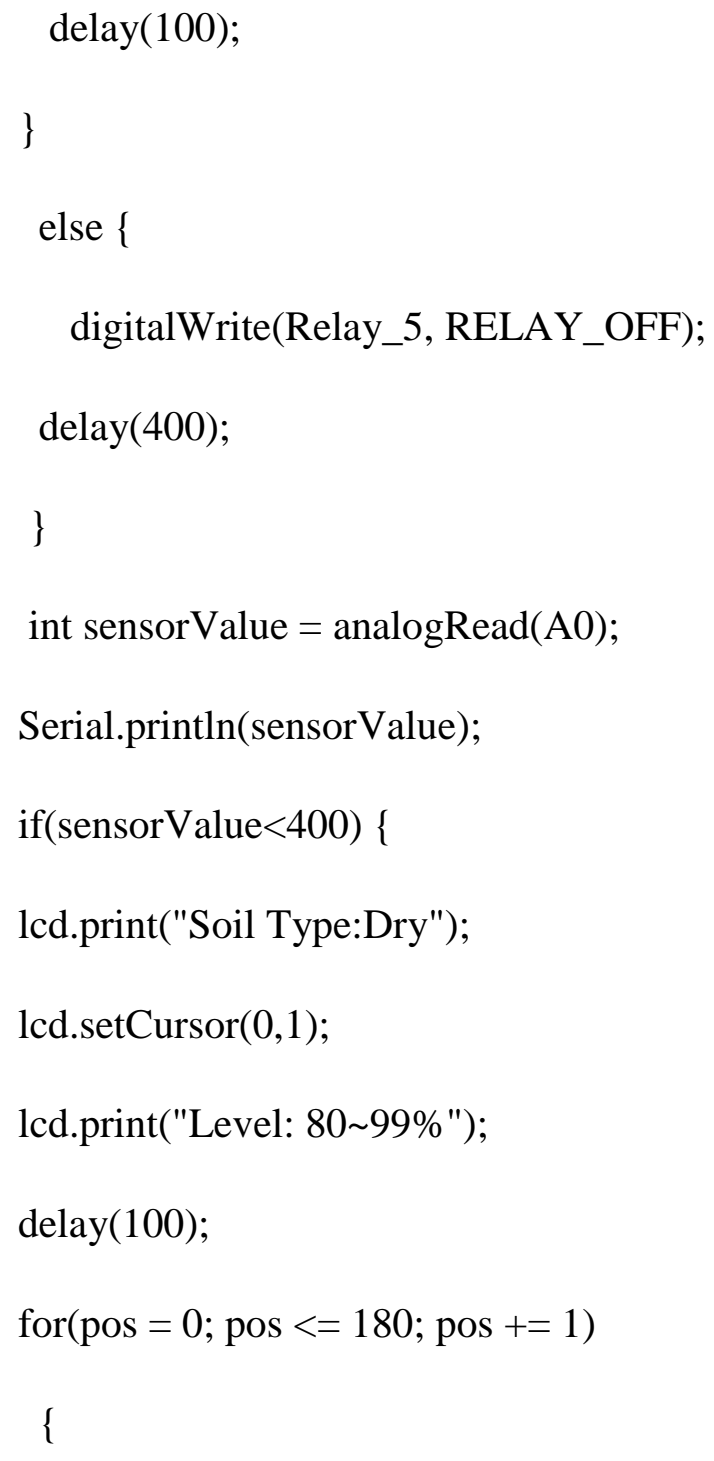




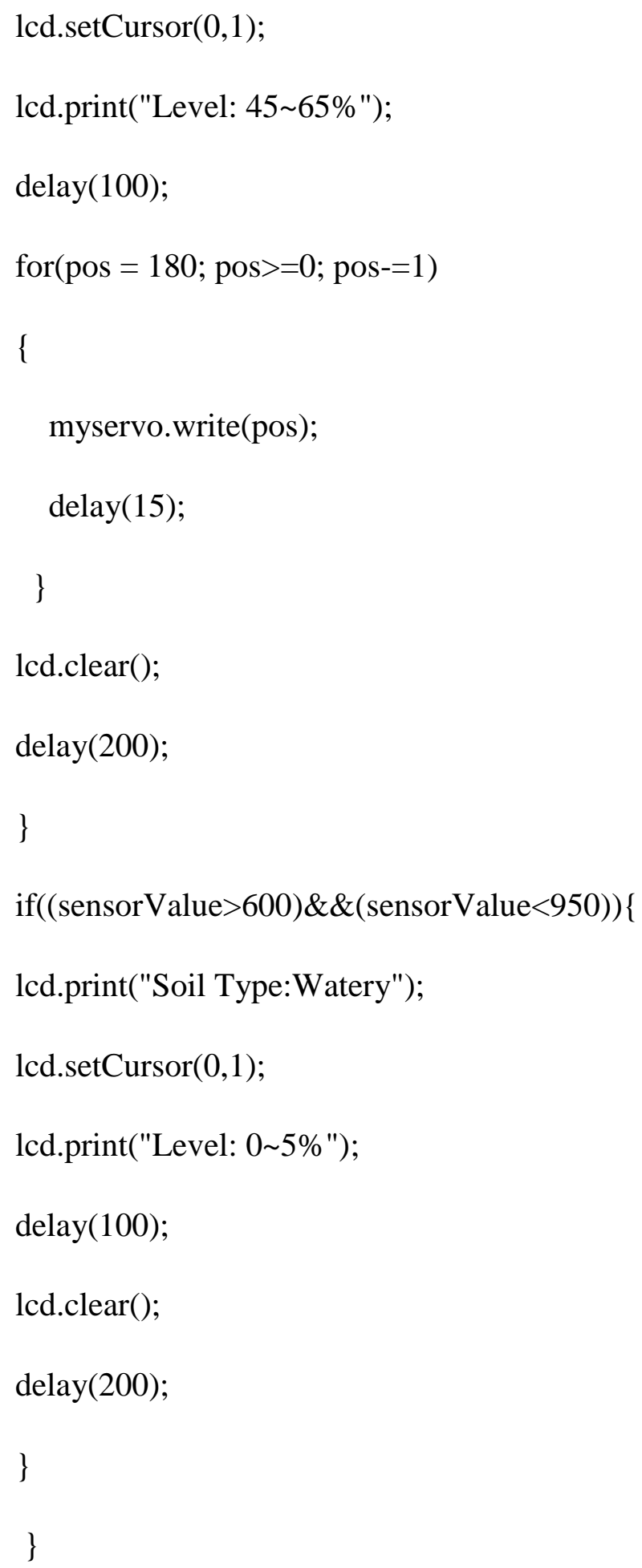




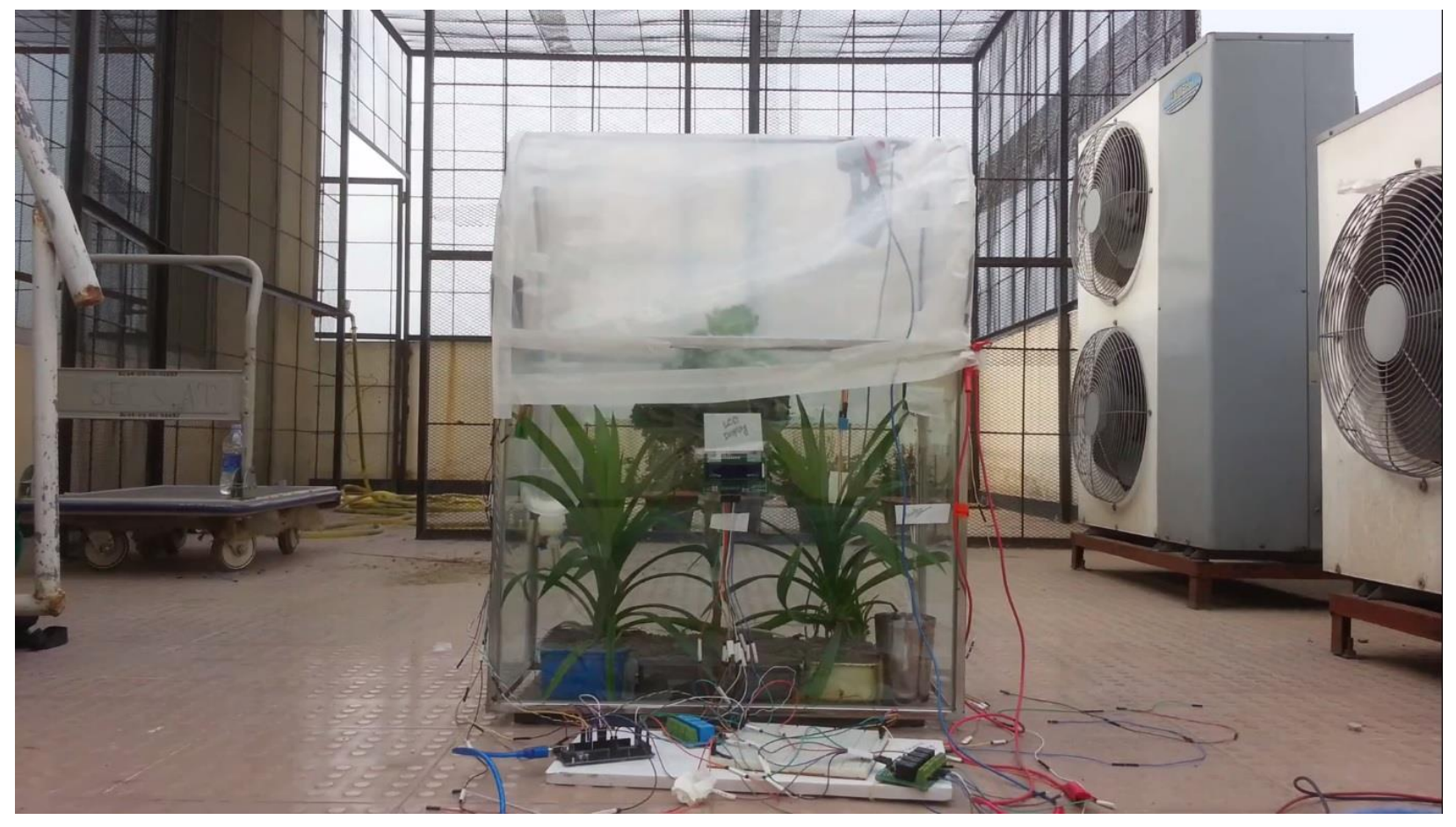

An Automatic Monitoring and Control System inside Greenhouse 